

\section{Telenovelas: origens, evolução e aspectos comerciais}

\author{
Soap operas: origins, \\ evolution and commercial aspects
}

\section{Jenara Miranda Lopes ${ }^{1} \boldsymbol{G}$}

\begin{abstract}
Resumo
A telenovela brasileira é um produto cultural que transmite valores e estilos de vida. Ela é um produto que visa o entretenimento e, eventuais explosões de consumo, geradas pelas telenovelas, são consequências do sucesso desse tipo de ficção junto ao seu público espectador, e suas origens remontam a peças publicitárias de produtos de higiene e beleza veiculadas nas rádios em meados do século XX. A relação entre as novelas e os telespectadores funciona como um caminho de duas vias, em que informação e consumo, referência e reprodução estão num ciclo constante, potencializado pelas redes sociais. A relação entre telenovelas e os diversos tipos de consumo é o que se propõe abordar neste artigo.
\end{abstract}

\section{Palavras-chave}

Telenovela; mídia; consumo; merchandising editorial.

\section{Abstract}

The Brazilian soap opera is a cultural product that diffuses values and lifestyles with the purpose of entertainment. Eventual mass consumption explosions, generated by soap operas, are the consequence of the success among its public. Its origins date back to the hygiene and beauty products advertisements on the radio, in the middle of the twentieth Century. The relationship between soap operas and viewers functions as a two-way road, where information and consumption, reference and reproduction are in a constant cycle, boosted by social networks. The relationship between soaps and the various types of consumption is what this article proposes to address.

\section{Keywords}

Soap opera; media; consumption; product placement.

63 PORTO ALEGRE | v. 20 | n. 34 | 2015 | pp. 63-71 DOI: http://dx.doi.org/10.15448/1980-3710.2015.2.22016 Sessões do Imaginário 
Para falar sobre a evolução da telenovela e sua relação com interesses comerciais, devemos revisar as suas origens. Nos anos 1940, chegou ao Brasil o que seria na época o sucesso entre os ouvintes na América Latina e Estados Unidos, a radionovela. Ligadas diretamente à publicidade, as radionovelas foram um gênero extremamente popular, voltado ao público feminino, principalmente donas-de-casa. Esses programas, além de serem patrocinados pelas grandes Indústrias Multinacionais, que importaram o gênero ao Brasil, tinham suas agências de propaganda como responsáveis pela criação e produção.

Tendo sido idealizada nos EUA, a soap opera surge na década de 1930 e se difunde nas rádios americanas. Concebida originalmente como veículo de propaganda das "fábricas de sabão", ela visava aumentar o volume de produtos e limpeza e toalete, comprado principalmente pelas mulheres. Com a expansão das empresas americanas na América Latina (Colgate, Lever) buscou-se aclimatar a american-soap ao interesse folhetinesco das mulheres latino-americanas. Nascem assim as radionovelas, que primeiramente florescem em Cuba sob o patrocínio dos produtores de sabão e detergente, e são em seguida exportadas para o resto do continente como técnica de venda e comercialização de produtos (Ortiz, 200, p. 44)

Nessa época, conhecida como "a época de ouro" do rádio no Brasil, as agências de propaganda tinham os seus próprios estúdios. Segundo Ortiz, "entre 1943 e 1945, a Rádio Nacional chegou a produzir 116 novelas num total de 2.985 capítulos" (Ortiz, 2001, p. 40). Alguns roteiristas de radionovela puderam ser vistos na televisão mais tarde, onde se consagraram grandes escrito- res do gênero novelístico, como, por exemplo, Janete Clair. O estilo preferido das histórias da radionovela era o melodrama, e se estenderia à telenovela quando do seu surgimento no Brasil, na década de 1950. Segundo Martín-Barbero,

a cumplicidade com o novo público popular e o tipo de demarcação cultural que ela traça são as chaves que nos permitem situar o melodrama no vértice mesmo do processo que leva do popular ao massivo: lugar de chegada de uma memória narrativa e gestual e lugar de emergência de uma cena de massa, isto é, onde o popular começa a ser objeto de uma operação, de um apagamento das fronteiras deslanchando com a constituição de um discurso homogêneo e uma imagem unificada do popular, primeira figura da massa. [...] A funcionalização da música e a fabricação de efeitos sonoros, que encontrarão nas novelas de rádio seu esplendor, tiveram no melodrama não só um antecedente, mas todo um paradigma (Martín-Barbero, 1997, p. 159)

Conhecida nos Estados Unidos como soap opera, a telenovela vem ao Brasil, também, importada pelas grandes indústrias do "sabão" e de higiene pessoal, exatamente como a sua antecessora, seguindo o mesmo modelo de programa patrocinado. Ortiz considera que, neste período "de 1951 a 1954, a telenovela existe como um prolongamento das radionovelas" (Ortiz, 2001, p 74). Além disso, falando sobre o papel da publicidade na produção dos programas, Ortiz diz que

[...] a agência de publicidade 'cuidava de tudo: escrevia, produzia, contratava elenco e até mesmo 'completava' o salário do pessoal técnico da emissora que se limitava a entrar com o parco equipamento existente e com o 'horário'. Os publicitários confirmam que em alguns casos havia quase uma inversão de papéis, pois a agência que produzia os programas deixava para a emissora simplesmente o trabalho de comercializar o espaço (Ortiz, 2001, p. 60).

Nesta época, os programas eram exibidos "ao vivo" e de modo precário, pois não existia uma estrutura de produção adequada ao novo veículo. Com o advento da TV Excelsior, esse cenário muda. A partir de 1954, as produções passam a adaptar textos estrangeiros, consagrados pela literatura popular internacional, se distanciando um pouco do melodrama e retomando o gênero folhetinesco (Ortiz, 1991). Conforme Daniel Filho, "existem alguns elementos que toda novela deve ter: o mocinho, a mocinha, a ingênua, o bandido, o filho perdido que não sabe quem são os pais verdadeiros, o velho, 0 jovem, o romance jovem" (Filho, 2001, p. 67).

A precariedade com que era feita a produção dos programas contribuiu para que a novela fosse considerada um gênero menor, pois não tinha a qualidade do cinema. Conforme a qualidade das produções foi aumentando, as novelas foram ganhando um maior espaço nas grades de programação. Programas que eram transmitidos com apenas 20 minutos passaram a ter um tempo de duração maior e, gradualmente, passaram a ser apresentados diariamente. Isso só foi possível através da profissionalização e da divisão de tarefas dentro do processo de produção, buscando esse conhecimento muitas vezes no exterior (México, Argentina, Venezuela), onde as telenovelas já eram um gênero consagrado pelo público. A primeira telenovela diária - 2-5499 ocupado, de Alberto Migré - foi ao ar em julho de 1963 pela TV Excelsior (Ortiz, 1991). Conforme Daniel Filho, 
as primeiras novelas eram traduções de produções argentinas e mexicanas, um ramo, ainda na época da TV Excelsior, dominado pelas agências de publicidade. Pelas Colgate-Palmolive da vida, que gerenciavam as novelas e diziam como deviam ser feitas. É de uma dessas agências que surge Glória Magadan (Filho, 2001, p. 32).

O surgimento e o desenvolvimento da tecnologia do videotape contribuíram para que o sucesso deste tipo de produção fosse possível. Outros avanços tecnológicos influenciaram na legitimação da telenovela com um gênero dramatúrgico de qualidade, entre eles o uso de equipamento digital, de câmeras de alta definição e, atualmente, a transmissão do sinal em alta definição. Este último, inclusive, permite que as telenovelas, bem como toda a programação televisiva, sejam captadas em dispositivos móveis, tais como tablets e celulares.

Com a consolidação da Rede Globo no cenário nacional, a grade de horários das novelas foi padronizada, assim como o formato e os gêneros apresentados nas tradicionais faixas de horários das $18 \mathrm{~h}, 19 \mathrm{~h}$ e $20 \mathrm{~h}$. Ao longo dos anos, essas faixas de horário foram se modificando e hoje temos cinco faixas de horário tradicionais, dedicadas à transmissão de novelas: 16h30 (reprises), 17 h30 (público jovem), 18h30, 19 h30 e 21h. Eventualmente, tem-se transmitido produções de curta duração na faixa de horário das $23 \mathrm{~h}$, com remakes de produções antigas e, mais recentemente, uma produção original: Verdades Secretas (Rede Globo, 2015). Segundo Ortiz,

é interessante observar que no Brasil a telenovela foi escolhida como o produto por excelência da atividade televisiva. Contrariamente aos EUA, onde a soap opera seguiu na televisão o esquema do rádio, se dirigindo a um público feminino durante o horário da tarde, a novela se transformou entre nós num produto prime time, e para ela convergiram todas as atenções (de melhoria do padrão de qualidade e dos investimentos) (Ortiz, 2001, p. 145).

A partir daí, temas diferentes foram abordados, alguns atraindo inclusive a audiência masculina. Segundo o Anuário 2013 do Obitel, “observa-se que há um aumento na porcentagem de público masculino na composição da audiência após as 21h (nas telenovelas Avenida Brasil e Salve Jorge e nas séries A Grande Família e Tapas \& Beijos)" (Lopes e Gomez, 201, p. 150). Conforme Daniel Filho,

em São Paulo, Cassiano Gabus Mendes captou isso E desse seu insightgenial surgiu em 1969 a novela Beto Rockfeller - um personagem do nosso cotidiano, vivendo aventuras e trapalhadas que qualquer um, com certa "prontidão" diante da vida e do mundo, poderia viver. O público começava a querer assistir na televisão coisas mais próximas da sua realidade (Filho, 2001, p. 35).

As novas tecnologias trazidas pela emissora, em função de um contrato com o grupo Time-Life, proporcionaram à televisão uma proximidade maior com o público, por fazer produções mais realistas e por introduzir o uso de cenas externas com maior regularidade.

Do ponto de vista da produção, pode-se dizer que as externas, que eram raras nos anos 60, tornam-se atualmente quase que obrigatórias. Dois motivos concorrem para isto. Primeiro, uma tendência ao realismo, que exige uma elaboração maior da imagem, segundo, o merchandising. São inúmeras as cenas ditadas pelo imperativo econômico de se anunciar algum produto - restaurantes, boates, refrigerantes (Ortiz, 1991, p. 139).

Segundo Renato Ortiz, quando na história a ser contada é introduzida uma série de signos e sinais da "realidade", isto tem por finalidade estabelecer uma ligação entre o que está sendo mostrado e situações da vida cotidiana (Ortiz, 1991). Para ele, o que interessa à telenovela é apresentar algo que o telespectador possa identificar, e a introdução de cenas em locações externas contribui para a percepção desses ambientes cotidianos. Sobretudo porque esses ambientes são familiares ao espectador - por exemplo: ruas e avenidas, praias e pontos turísticos de cidades como o Rio de Janeiro - e, dessa forma, prendem sua atenção. Conforme Jost

uma novela pode ser percebida tanto como uma ficção, como também uma peça que trata dos documentos da tela, isto é, como um documento sobre a realidade. No contexto televisual, a emissora é a instância, se assim se pode chamar, de onomaturgia, que decide ou propõe - a nuance tem importância -, a générécité do produto (Jost, 2004, p. 28).

Maria Rita Kehl coloca a evolução da narrativa das telenovelas em dois momentos: a da inclusão de temas realistas e, mais tarde, a adoção de uma estética naturalista. Essa evolução narrativa e estética, pela qual passaram as telenovelas ao longo dos anos, só foi possível graças à evolução técnica pela qual a televisão passou. Segundo ela, "na novela, o realismo do começo dos anos 1970 descambou rapidamente para um naturalismo altamente sofisticado quanto às suas possibilidades 
técnicas de mimetizar as aparências do real" (Kehl, 1986, p. 278). Apesar de ter passado por evoluções na linguagem ao longo dos anos, pouco mudou em relação à estrutura básica de uma novela, que ainda mantém os traços herdados do melodrama.

A matriz melodramática permanece como dominante nas produções, porém, o modo como acontecem os desdobramentos desses temas, colocados num contexto brasileiro contemporâneo, faz surgir abordagens inovadoras ou, no mínimo, questionadoras, na medida em que dão ênfase a questões polêmicas, sejam sociais ou morais, como, por exemplo, a corrupção. O reconhecimento de novos atores sociais, com a chamada "nova classe média" ou "nova classe C" ganhando força no mercado consumidor, fez com que novos cenários, comunidades e comportamentos também ganhassem espaço nas produções audiovisuais de um modo geral, em especial nas telenovelas, tendo a periferia uma presença significativa em produções como Avenida Brasil (Rede Globo, 2012) e Salve Jorge (Rede Globo, 2012), Babilônia (Rede Globo, 2015) e A Regra do Jogo (Rede Globo, 2015), para citar algumas produções do horário das $21 \mathrm{~h}$.

Pelo fato de permanecerem durante muitos meses no ar, as telenovelas estão sujeitas às mudanças no roteiro previstas, ou não, pelos autores. Alguns deles fazem modificações ao longo do período de exibição por conta de flutuações de audiência e, além disso, o modo como um ator/atriz conduz seu personagem também faz com que ele tenha uma visibilidade junto ao público que não era prevista no início das tramas. Alguns personagens, inclusive, que estão previstos para sair das produções (morrer, viajar, etc.) acabam permanecendo por mais tempo a pedido do público. Sobre isso, Daniel Filho diz que
Ao escrever uma novela, o autor não deve começar já muito preparado para o que poderá acontecer posteriormente na história. Como obra aberta, tem muita estrada do primeiro ao último capítulo. A novela ganha vida quando toda a equipe trabalha sobre ela: a trilha sonora, os cenários os figurinos, o trabalho dos atores. Pode até haver falta de química entre atores, ou entre o ator e seu personagem. Depois da estreia ainda pode haver problemas com a audiência, doença de atores e outros incidentes (Filho, 2001, p. 70).

Essa interferência do público nas tramas tem se intensificado na medida em que os canais de interação com as produções vêm também aumentando. Segundo pesquisas do Obitel, cada vez mais o público tem consumido os conteúdos televisivos em multiplataforma: ao mesmo tempo em que assiste à televisão, por exemplo, utiliza aplicativos para tablets, navega em páginas oficiais das produções na internet e em redes sociais como Facebook e Twitter - especialmente as telenovelas, tendo utilizado, sobretudo, as redes sociais para conversações e apreciações sobre estas, consumindo e gerando conteúdo sobre essas produções (Lopes e Gomez, 2013). De acordo com - Anuário de pesquisas do grupo, Avenida Brasil (Rede Globo, 2012) foi a produção cujo engajamento dos telespectadores representou um marco no que diz respeito a novos modos de se consumir as telenovelas:

a telenovela Avenida Brasil marcou a história da televisão brasileira no que se refere a índices de engajamento da audiência com a trama ficcional do horário nobre, repercutindo de maneira surpreendente diante do atual contexto de espalhamento das audiências e consumo de conteúdos em multiplataformas. Um dos reflexos desse êxito foi o volume de conteúdos gerados por produtores e usuários sobre a ficção, propagado nas redes sociais, fato que chamou a atenção da imprensa internacional. As hashtags \#avenidabrasil e \#oioioi ( $+\mathrm{n}^{\circ}$ do capítulo) foram, ao longo da última semana da telenovela, Tops no Twitter WorldwideTrends. As alterações na agenda da presidente da República e o transbordamento da temática da telenovela para a inteira programação da Globo, criando um reforço das expectativas por contágio dos programas, às vésperas da exibição do último capítulo na TV, também são indicativos do fenômeno. Nas redes, dois fatores contribuíram para o engajamento e a transmidiação do conteúdo ficcional de Avenida Brasil: o hábito dos brasileiros de assistir TV ao mesmo tempo em que buscam e geram conteúdos sobre a grade horária nas redes sociais, e o volume de conteúdos gerados pelo produtor na fanpage da Rede Globo e na página oficial da telenovela no Facebook, que reuniu aproximadamente meio milhão de fãs (Lopes e Gomez, 2013, p. 151).

Outro aspecto relativo à maneira como são consumidas as telenovelas e os conteúdos provenientes delas são as revistas. Especializadas em telenovela e voltadas para as classes populares, essas revistas publicam os resumos da semana e também antecipam os acontecimentos que estão por vir nas tramas. Essa prática intensifica a visibilidade das telenovelas através de meios e veículos, como a imprensa - diariamente e em encartes específicos e semanais sobre televisão - e grandes portais de entretenimento e notícias da internet, que não estão vinculados diretamente com as emissoras, mas que se valem do poder de venda que estas produções possuem. Embora esses resumos tenham a finalidade de manter o espectador atualizado com os acontecimentos das novelas, 


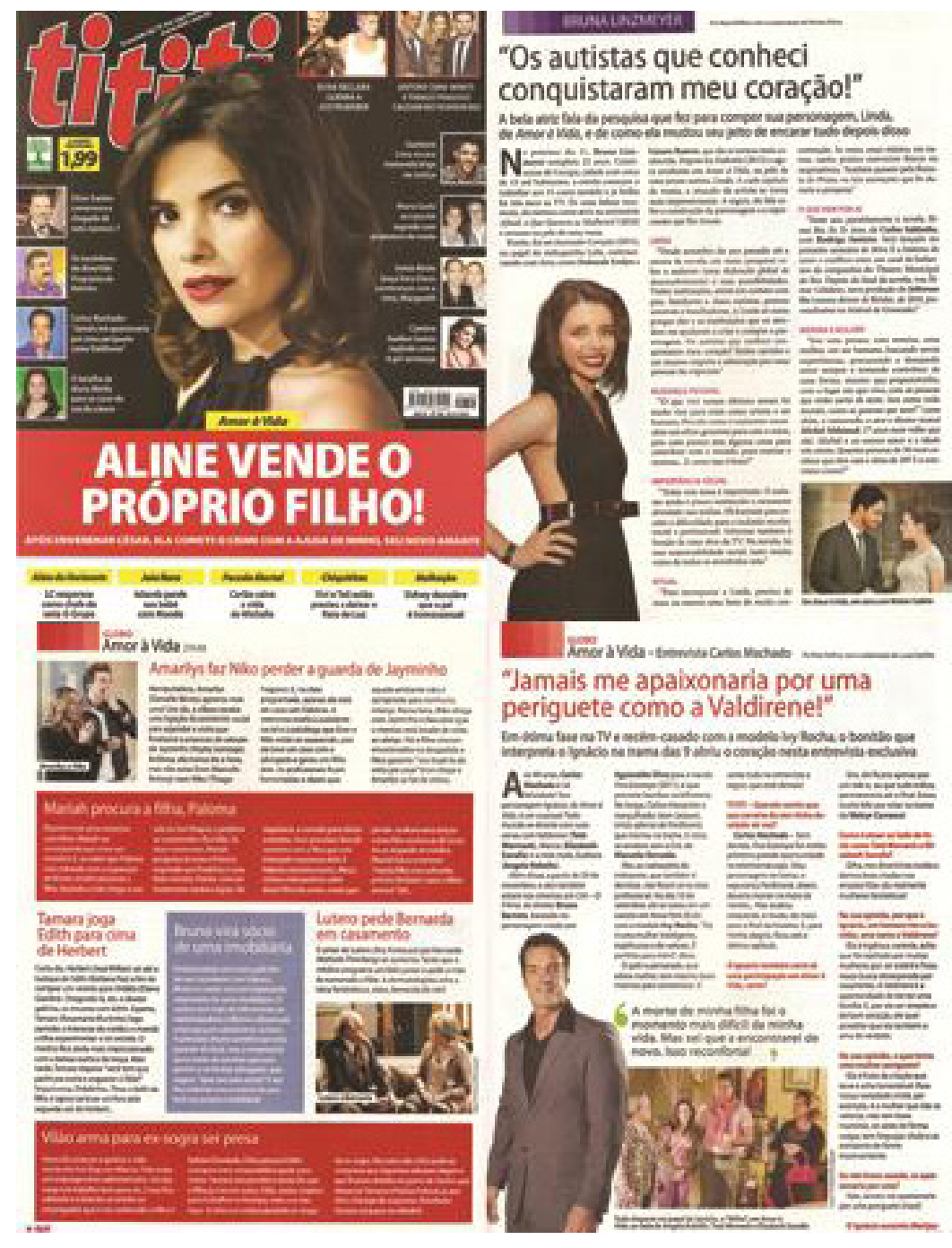
conquistaram meu coração!"

29

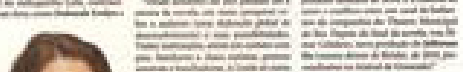

Novelas

Aline vende o próprio filho!

A

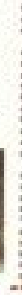

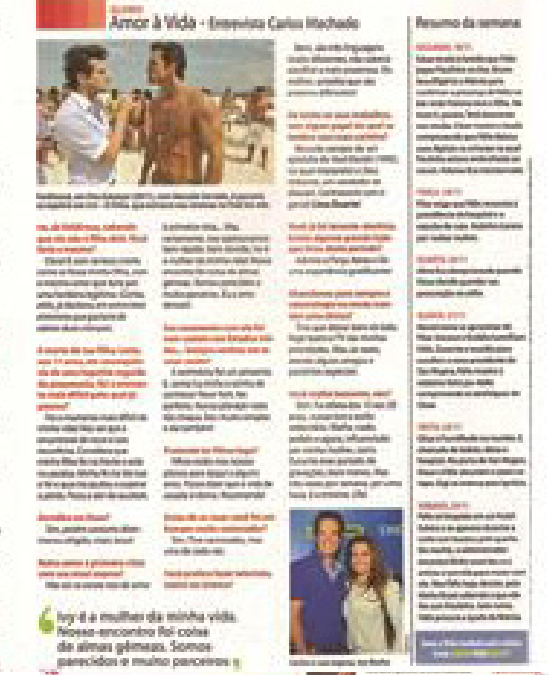

Figura 1: Revista Tititi (2012), p. 21, 28-32.

sobretudo quando este não consegue assistir aos capítulos no momento da sua exibição e/ou em outras plataformas, muitos dos telespectadores usam esses canais de informações mesmo sendo assíduos, de forma paralela à transmissão dos capítulos pelas emissoras, criando uma prática de consumo que poderíamos, também, considerar como transmidiática. Essas mesmas revistas incluem entrevistas com o elenco das produções, descrevendo os perfis desses atores e atrizes e, por vezes, fazendo especulações sobre o futuro de seus personagens nas tramas. Dois exemplos de publicações com essas características que podemos citar são as revistas Tititi (Figura 1) e Minha Novela (Figura 2)2 , ambas da Editora Abril.

São revistas semanais, com preços populares e linguagem simples, que reúnem informações sobre as telenovelas exibidas pelas diferentes emissoras brasileiras de televisão aberta. Contudo, são as telenove- las exibidas pela Rede Globo, no horário das $21 \mathrm{~h}$, que ganham maior destaque em ambas as revistas, com conteúdos ocupando geralmente as páginas centrais.

\section{Merchandising editorial e licenciamento}

Tendo feito uma breve trajetória histórica das telenovelas, passamos para os aspectos comerciais, como licenciamento e merchandising editorial, presentes nessas produções e que estão diretamente ligados ao consumo. A telenovela jamais atingiria o estágio em que se apresenta hoje se não fosse, desde o início, patrocinada. Desde a sua concepção, a novela teve a sua veiculação atrelada a interesses comerciais de empresas que não se escondiam ao usá-la para anunciar suas grifes e produtos. Segundo Lipovetsky, "a cultura de massa é uma cultura de consumo, inteiramente fabricada para o prazer imediato e a recreação do espírito, devendo-se sua sedução em parte à simplicidade que manifesta" (Lipovetsky, 2006, p. 210).

E não apenas serve como divulgadora de hábitos de consumo, como ela mesma se tornou um produto de exportação nacional, consumido em diversos países do exterior. O Bem Amado (TV Globo, 1973) foi a primeira telenovela exibida em cores a ser exportada para o exterior. Além disso, há a venda das trilhas sonoras também muito consumidas. Em 1965, foi lançado, no mercado nacional, o primeiro "LP" com trilha musical de novela. Essa tradição se confirma com a criação da gravadora Som Livre, em 1969, pela Rede Globo. Conforme Ortiz,

o processo de escolha e de produção da trilha musical tornou-se mais complicado, na medida em que se vincula a interesses comerciais consideráveis. A TV Globo 'descobriu' que a trilha sonora podia ser 
um produto mercadológico independente da própria novela (Ortiz, 1991, p. 146).

Mas foi nos anos 1970 que as vendas de LP's com as trilhas sonoras das telenovelas ganharam força. Segundo Ortiz,

[...] a Som Livre, vinculada à Rede Globo de Televisão, se especializou no ramo das músicas de novelas, deslocando do mercado inclusive as multinacionais. Iniciando suas atividades em 1970 com o compilado da trilha sonora da novela "O Cafona", já em 1976 se torna líder do mercado fonográfico, e em 1982 detém $25 \%$ do seu faturamento. (Ortiz, 2001, p. 128)

Após a consagração das novelas como grande sucesso de público e audiência no Brasil, as emissoras iniciaram uma prática comercial diferenciada, a ação de merchandising editorial entre as cenas, chamado inicialmente de merchandising por conta de os programas serem considerados como vitrines para os consumidores. Quando falamos em merchandising editorial, cujo nome usado em outros países é Product Placement ou Tie-In, falamos das aparições sutis de produtos em novelas, na marca estampada virtualmente em um evento esportivo ou numa demonstração de produto dentro de um programa de auditório (Blessa, 2011). Os primeiros grandes cases foram as telenovelas Dancing Day's (TV Globo, 1979), com as calças jeans Staroup, da personagem Júlia (Sônia Braga), e Água Viva (TV Globo, 1980) com a USTop (Souto Maior, 2006). A justificativa de se realizar essas ações é tornar viável a exibição desse produto cultural nos meios de comunicação, devido ao alto custo de sua produção, de modo que, ao atrair investimentos de
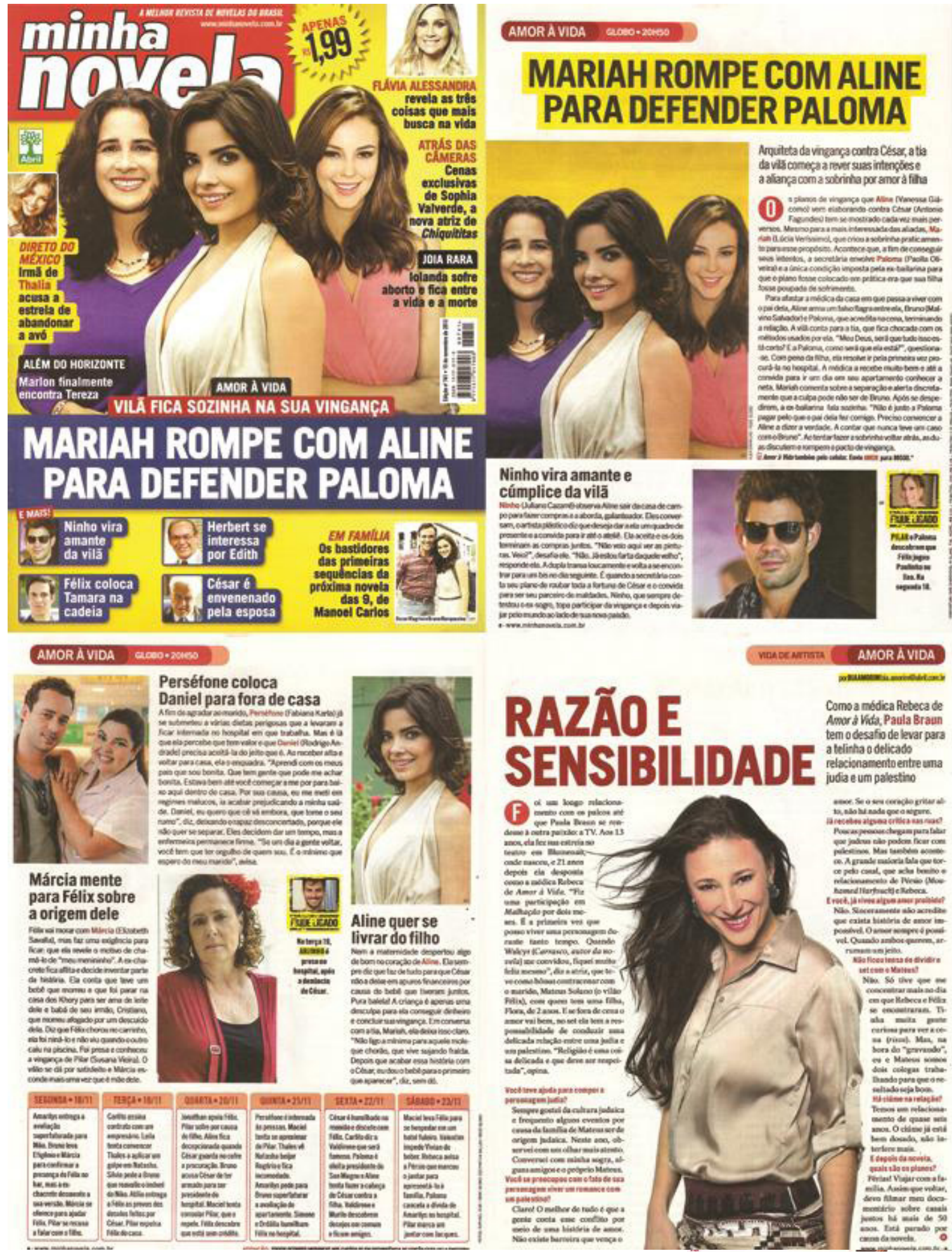

Figura 2: Revista Minha Novela, p. 6-9, (2012).

68 PORTO ALEGRE | v. 20 | n. 34 | 2015 | pp. 63-71 Sessões do Imaginário 
produtos com potencial de inserção dentro do contexto dessas produções, proporciona-se maior visibilidade às marcas.

Com o surgimento das plataformas VOD (Video On Demand) e a possibilidade de assistir aos programas em qualquer horário e lugar e sem intervalos, muitos canais de televisão internacionais passaram a adotar as práticas de licensing - licenciamento de produtos com as marcas dos programas de televisão e/ou nome e imagem de personagens para serem vendidos no varejo diretamente ao público - e product placement ${ }^{3}$ (Phillips, 2005).

As rotinas de consumo de bens culturais produzidos pela televisão - que incluem o consumo das telenovelas - acabam, também, influenciando no modo como os investimentos de anunciantes vão assumindo dinâmicas diferentes. No Brasil, houve um significativo aumento no investimento em merchandising editorial nos últimos três anos. Nesse cenário de convergência midiática e mudança nos modos de consumo, em que vemos empresas de televisão atuando com tecnologias da internet e empresas de internet produzindo e distribuindo conteúdo de televisão (Lopes e Gómez, 2013), podemos dizer que os investimentos estão se deslocando cada vez mais para o product placement. Além disso, o endosso de produtos por celebridades e artistas confere às marcas ainda mais visibilidade e, por vezes, credibilidade (Solomon, 2011, p. 304).

No caso das telenovelas, os tipos de merchandising editorial mais aplicados são o "estímulo visual" - que, em 2012, teve um investimento de aproximadamente 114 milhões de reais - e a "ação integrada" - que teve o investimento de aproximadamente 818 milhões de reais, no mesmo ano (Mídia Dados Brasil, 2013). Entre a programação que mais atrai investimentos em merchandising editorial, que é o carro chefe da programação nacional e se transformou em produto de exportação da Rede Globo, estão as telenovelas. Essa dinâmica dos investimentos em inclusão das marcas na programação, não só nos intervalos comerciais, se deve em parte à possibilidade de os espectadores assistirem a essa programação em $V O D$, como já citado anteriormente. A Rede Globo, emissora que detém as maiores fatias de audiência da televisão brasileira ${ }^{4}$, já disponibiliza um serviço de assinaturas que permite acessar os programas na íntegra, em qualquer horário via internet e dispositivos móveis.

Em relação ao uso do licenciamento de marcas pela Rede Globo, acessando o endereço eletrônico globomarcas.com o telespectador tem acesso à loja virtual da emissora, que vende produtos licenciados de todos os tipos, inclusive reproduções de peças utilizadas nos cenários e figurinos. O catálogo também dispõe de publicações da Editora Globo, CD's e DVD's da Som Livre, boxes de programas novos e antigos exibidos pela emissora e de filmes distribuídos pela Globo Filmes, além de conteúdos dos canais por assinatura GNT, Canal Brasil, Futura, Sportv e de eventos esportivos e culturais transmitidos e/ou patrocinados pela empresa, como, por exemplo, o Rock in Rio. Tendo iniciado parcerias com indústrias e empresas varejistas em 2004, um ano depois a emissora já contava com 1441 produtos licenciados (Sobral, 2005).

O licenciamento de marcas e o merchandising editorial são os modos mais explícitos de como o consumo pode estar presente nas telenovelas. Mas as peças que são usadas no figurino e no cenário - e que não são disponibilizadas para venda pela Globomarcas - também despertam o interesse do público consumidor, que precisa buscar essas informações através de outros canais, como, por exemplo, o Serviço de Atendimento ao Telespectador (SAT) da Rede Globo. Nessa central de atendimento por telefone, os dados sobre os itens de figurino das novelas - as marcas - são catalogados por capítulo e personagem e indicados ao espectador conforme seu pedido. Outro meio através do qual é possível descobrir quais marcas são usadas nos figurinos e nos cenários é através de blogs e revistas de moda, estilo e comportamento que buscam essas informações através do SAT ou de divulgações feitas pela própria produção das novelas.

Com a possibilidade de interação direta entre as empresas e seus consumidores - proporcionada pela internet, sobretudo pelas redes sociais - outra forma de divulgação das peças que compõe o guarda-roupa de um personagem é através dos blogs e fanpages das marcas. Um exemplo que podemos citar é o da grife mineira Alphorria, que divulga imagens das personagens de novela que vestem suas roupas. Como foi o caso da novela Salve Jorge (Rede Globo, 2012), com as personagens "Helô" - Giovanna Antonelli - e Lívia - Cláudia Raia - (Figura $3^{5}$ ), que tiveram a imagem publicada na fanpage do Facebook e em seu blog ${ }^{6}$, junto com as informações de outras novelas da Rede Globo e seus personagens.

Esta prática tem sido cada vez mais recorrente, bem como a promoção dos figurinos pela própria emissora, divulgando estas informações através de press releases, eventos com editoras de revistas e blogueiras de moda, ou mesmo nos sites das próprias novelas, como dicas de tendências de moda e beleza, num esforço de aproximação das produções com o público através do consumo desses produtos, que não raro se tornam assunto em redes sociais, entre amigos ou em locais de consumo como lojas e salões de beleza. Por não se tratar de marcas específicas, como ocorre no merchandising editorial, os números resultantes do consumo destes produtos são mais difíceis de serem mensurados estatisticamente, podendo, apenas, ser observados 


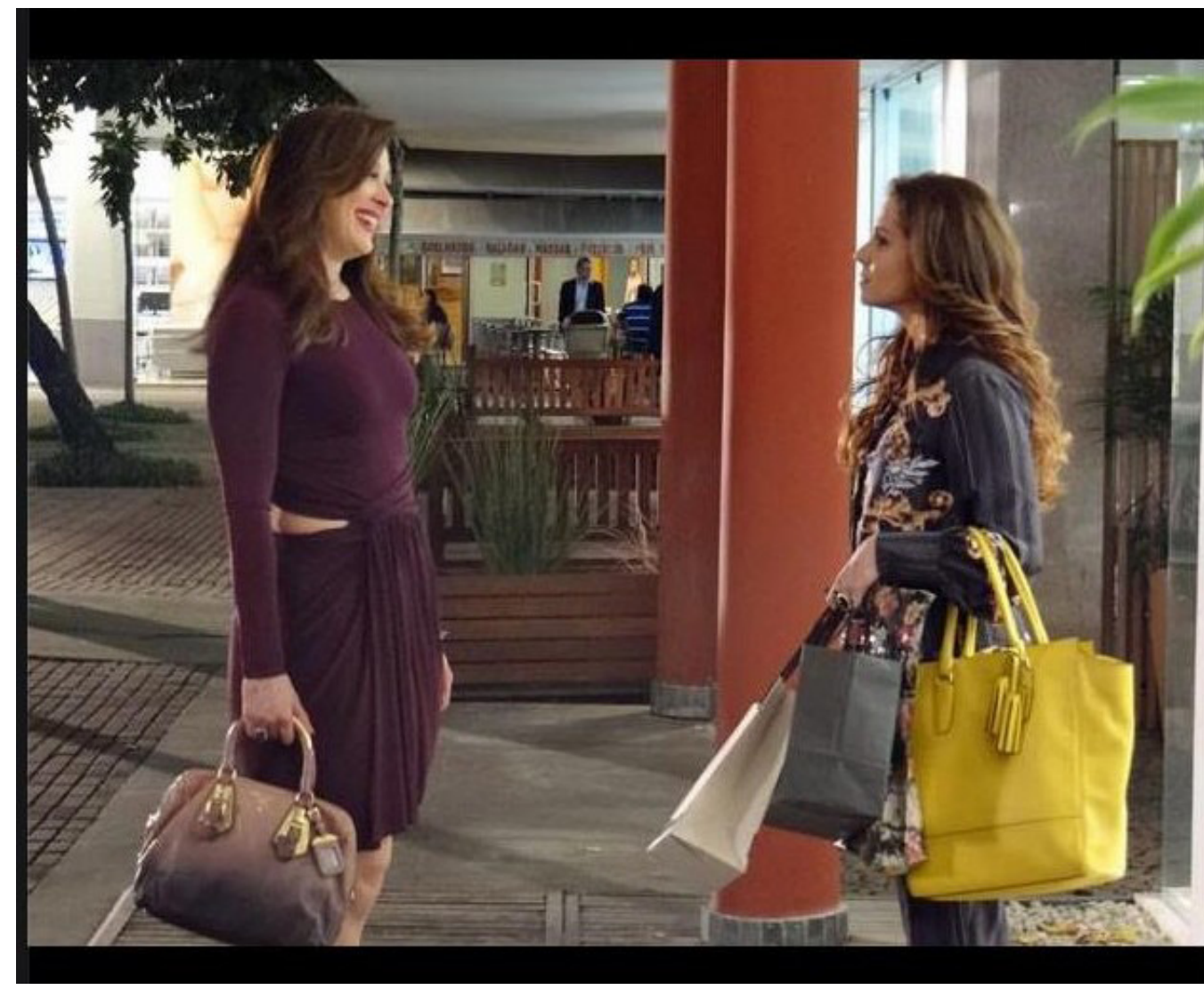
shopping da Zona Oeste do Rio de Janeiro teve a

Figura 3 - Fanpage da marca Alphorria (Facebook, abril/2013)

informalmente, o que não os torna menos presentes no dia-a-dia dos consumidores e nem menos importantes. Esse consumo informal e o porquê de as telenovelas gerarem o impulso de compra desses produtos em seus espectadores foi o que motivou o desenvolvimento da pesquisa que deu origem a este artigo.

\section{Referências}

BLESSA, Regina. Merchandising no ponto-de-venda. São Paulo: Atlas, 2011.

BLOG [da] ALPHORRIA. Disponível em: <http://www. blogalphorria.com.br/>. Acesso em: dez. 2013.
$\Lambda$

ALPHORRIA

Curtiu $\cdot 8$ de abril de 2013

Na última semana, quem estava passeando em um chance de encontrar parte do elenco de Salve Jorg gravando algumas cenas no local.

Giovanna Antonelli (Helô) e Claudia Raia (Lívia) estavam por lá. E o melhor: ambas vestidas com peças das nossas marcas.

Cláudia Raia usava um vestido da ALPHORRIA, da nossa coleção de outono. A peça tem recortes diferenciados, que valorizam a silhueta e deixam vestido ainda que varizam a sí cota e dexam o conjuntinho da A.Cult que já virou hit entre as mais antenadas! Adoramos! 0

Curtir · Comentar · Compartihar

al 100 pessoas curtiram isso.

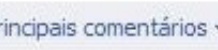

들 50 compartihamentos

P. Vivianne Louise de Oliveira Tem no ri2 Aonde contro pecas aqui no ri?

creva um comentário.

× LIPOVETSKY, Gilles. 0 império do efêmero: a moda e seu destino nas sociedades modernas. São Paulo: Companhia Das Letras, 2006.

LOPES, Maria Immacolata Vassalo de; GÓMEZ, Guillermo Orozco (coord.). Memória social e ficção televisiva em países ibero-americanos: anuário Obitel 2013. Porto Alegre: Sulina, 2013.

MARTIN-BARBERO, Jesus. Dos meios às mediações: comunicação, cultura e hegemonia. Rio de Janeiro: UFRJ, 1997.

MíDIA Dados Brasil 2013. Disponível em: <https:// mdb2013.bbi.net.br/>. Acesso em: jul. 2013.

MINHA NOVELA. São Paulo: Abril, 1999 -. Mensal. ISSN 1517-0179. N. 741.

ORTIZ, Renato et. al. A moderna tradição brasileira. 5. ed. São Paulo: Brasiliense, 2001.

ORTIZ, Renato. Telenovela: história e produção. 2. ed. São Paulo: Brasiliense, 1991.

ALPHORRIA. Disponivel em: $<$ https:/ so em: dez. 2013.

FILHO, Daniel. O circo eletrônico: fazendo TV no Brasil. Rio de Janeiro: Jorge Zahar Ed., 2001.

JOST, François. Seis lições sobre televisão. Porto Ale

PHILLIPS, Simon. Licensing Authority: TV product placement hits international snag. Promotions \& Incentives, Londres, Maio, 2005. Disponível em: <http://search. proquest.com/docview/232096887? accountid=8034>. Acesso em: 31 mai. 2012.

SOBRAL, Eliane. Emissoras de TV do Brasil ampliam licenciamento de marcas. Noticias Financieras, Miami, 9 set., 2005. Disponível em: <http://search.proquest.com/docKEHL, Maria Rita; SIMÕES, Inimá F.; COSTA, Alcir Henrique da. Um país no ar. São Paulo: Brasiliense, 1986. view/465958539? accountid=8034>. Acesso em: 23 maio, 2012.

70 PORTO ALEGRE | v. 20 | n. 34 | 2015 | pp. 63-71 Sessões do Imaginário 
SOLOMON, Michael R. O comportamento do consumidor: comprando, possuindo e sendo. Porto Alegre: Bookman, 2011. pp. 129-131.

SOUTO MAIOR, Marcel. Almanaque TV Globo. São Paulo: Globo, 2006

TITITI. São Paulo: Abril, 1997 -. Mensal. ISSN 1415-974-0. N. 792.

\section{Notas}

1 Mestre em Comunicação Social pela PUCRS. Especialista em Imagem Publicitária pela Pontifícia Universidade Católica do Rio Grande do Sul (2007) (Av. Ipiranga, 6681, prédio 7, sala 319, CEP: 90619-900 - Porto Alegre/ $\mathrm{RS}$, Brasil). Atua como pesquisadora das áreas de audiovisual, moda, design, figurino e consumo. E-mail: jenara.lopes@acad.pucrs.br

2 Os conteúdos de ambas as figuras remetem à telenovela Amor à Vida, exibida pela Rede Globo no horário das 21h, em 2013.
3 Inserção de produtos com a divulgação de marca dentro do contexto das produções- com a finalidade de cobrir as perdas de investimento em comerciais, possibilitando às marcas alcançar o espectador através dos próprios programas.

4 A emissora apresenta um share de $32 \%$ no período matutino (7 às 12 horas), de 39,98\% no período vespertino (12 às 18 horas) e de $51,68 \%$ no período noturno (das 18 às 24 horas). Cf. IBOPE Media Workstation - 2012. In: Mídia Dados Brasil 2013. Op. cit.

5 Imagem da novela Salve Jorge (Rede Globo, 2012), publicada na página da Alphorria, no Facebook, em 8 de abril de 2013. Disponível em: <https://www.facebook. com/UniversoAlphorria?fref=ts $>$. Acesso em: dez. 2013.

6 Ver Blog Alphorria. Disponível em: $<$ http://www.blogalphorria.com.br/>. Acesso em: dez. 2013. 